\title{
Tuning the Stoichiometry of Lanthanide Complexes with Calixarenes: Bimetallic Complexes with a Calix[6]arene Bearing Ether-Amide Pendant Arms
}

\author{
Flor de María Ramírez, ${ }^{[\mathrm{a}, \mathrm{b}]}$ Loïc Charbonnière, ${ }^{[\mathrm{cl}}$ Gilles Muller, ${ }^{[\mathrm{a}, \mathrm{d}]}$ and \\ Jean-Claude G. Bünzli*[a]
}

Keywords: Lanthanides / Calixarenes / Europium / Luminescence

A de-tert-butylated calix[6]arene $\left(\mathrm{A}_{6} \mathrm{~L}^{6}\right)$ fitted with six etheramide pendant arms was synthesized and characterized in solution. NMR spectroscopic data point to the six phenoxide units adopting an average $D_{6 h}$ conformation on the NMR time scale. According to MM3 molecular mechanics, and MOPAC quantum mechanical calculations, $\mathrm{A}_{6} \mathrm{~L}^{6}$ is a ditopic ligand featuring two nonadentate coordination sites, each built from three pendant arms, and extending in opposite directions with one above, and the other under the main ring. $\mathrm{A}_{6} \mathrm{~L}^{6}$ reacts with $\mathrm{Ln}{ }^{\mathrm{III}}$ ions ( $\mathrm{Ln}=\mathrm{La}, \mathrm{Eu}$ ) in acetonitrile to successively form 1:1 and 2:1 complexes. The isolated $\mathrm{Eu}^{\mathrm{III}}$ 2:1 complex is luminescent (quantum yield: $2.5 \%$ in acetonitrile, upon ligand excitation). In the solid state, the luminescence decay is bi-exponential, with lifetimes equal to 1.66 and 0.46 $\mathrm{ms}$ (upon direct metal excitation), pointing to the presence of two differently coordinated metal ions, one with essentially no bound water molecules, and the other one with two ligated water molecules. According to molecular mechanics calculations, the more stable isomer is indeed asymmetric with two nine-coordinated metal ions. Both $\mathrm{Eu}^{\mathrm{III}}$ ions are bound to three bidentate arms, and one monodentate triflate anion, but one metal ion completes its coordination sphere with two phenoxide oxygen atoms, and the other one with two water molecules, consistent with IR spectroscopic and luminescence data. In acetonitrile solution, the two metal ion sites become equivalent, and the relatively long lifetime (1.35 ms) is indicative of a coordination environment free of water molecules. This work demonstrates, that the stoichiometry of lanthanide complexes with calixarenes can be tuned by a suitable choice of the narrow and/or wide rim substituents. (c) Wiley-VCH Verlag GmbH \& Co. KGaA, 69451 Weinheim, Germany, 2004)

\section{Introduction}

Calixarenes act as versatile building blocks in supramolecular and coordination chemistry, since both their lower and upper rims may be derivatized to induce specific functionalities. ${ }^{[1,2]}$ They are currently being used in the design of chemical sensors, ${ }^{[3]}$ catalysts,,${ }^{[4]}$ and selective ligands for the complexation of $\mathrm{d}^{[5]}$ and $\mathrm{f}^{[6,7]}$ metal ions, as well as for the self-assembly, through $\pi$-stacking, H-bonding or coordination interactions, of elaborate supramolecular structures. ${ }^{[8,9]}$ As a consequence, many studies have aimed

[a] Institute of Molecular and Biological Chemistry, Swiss Federal Institute of Technology,

BCH 1402, 1015 Lausanne, Switzerland

E-mail: jean-claude.bunzli@epfl.ch

[b] Instituto Nacional de Investigaciones Nucleares, Departamento de Química,

Km 36.5 Carretera México-Toluca, Apartado Postal 111, Lerma, Edo. de México, C.P. 52045, Mexico

[c] École de Chimie, Polymères et Matériaux, Laboratoire de Chimie Moléculaire, UMR 7008 CNRS,

25 rue Becquerel, 67087 Strasbourg Cedex 2, France

[d] Department of Chemistry, University of Minnesota Duluth, MN 55812-3020, USA

Supporting information for this article is available on the WWW under http://www.eurjic.org or from the author. at using calixarenes for the development of separation processes, ${ }^{[10]}$ and the nuclear industry is particularly interested in these ligands for the separation of highly radioactive actinides from non-radioactive lanthanides before nuclear waste confinement. ${ }^{[1-13]}$

In recent years, we have been developing model calixarene molecules for the study of energy migration mechanisms in luminescent lanthanide-containing compounds, and of magnetic $4 \mathrm{f}-4 \mathrm{f}$ interactions. ${ }^{[7]}$ We have also been interested in calixarenes having $4 \mathrm{f}-5 \mathrm{f}$ separation capabilities. This leads to the formation of luminescent $4 \mathrm{f}$-species which can be easily analyzed during the extraction process. With this in mind, we have focused on two series of branched calixarenes, one bearing ether-amide pendant arms A, and the other having phosphanylyl groups B (see Scheme 1). The ether-amide substituent was designed so that it can act as a bidentate ligand forming a five-membered cycle upon coordination of its ether and amide functions to trivalent lanthanide ions $\mathrm{Ln}^{\mathrm{III}}$. We have shown that $\mathrm{A}_{4} \mathrm{bL}^{4}$ acts as an inorganic-organic receptor, encapsulating both a lanthanide ion and a solvent molecule. In addition, the crystal structure of the $\mathrm{Lu}^{\mathrm{III}} 1: 1$ complex shows the coordination cavity predisposed to further accommodate one 
water molecule hydrogen-bonded to the oxygen atoms of the phenol units, which rigidifies the induced cavity, and binds the metal ion. ${ }^{[14]}$ The phosphanylyl-substituted calixarenes $\mathrm{B}_{n} \mathrm{bL}^{n}(n=4,6)$ form complexes with 1:1 and 1:2 $\mathrm{Ln}^{\mathrm{III}}$ ligand ratios having significant stability in acetonitrile, ${ }^{[15,16]}$ and interesting luminescent ${ }^{[15,16]}$ and $4 f-5 f$ separation $^{[17]}$ properties. Several derivatized calix[6]arenes have been tested in extraction studies ${ }^{[18-20]}$ and, in our case, $\mathrm{B}_{6} \mathrm{bL}^{6}$ proved to be a better extracting agent than $\mathrm{B}_{4} \mathrm{bL}^{4} \cdot{ }^{[17]}$ Despite that calix[6]arene complexes with lanthanide ions have also been proposed as luminescent probes, ${ }^{[21,22]}$ little is known about the interaction between calix[6]arenes and $\mathrm{Ln}^{\mathrm{III}}$ ions. The reaction of europium nitrate with $p$-tert-butylcalix[6]arene leads to the formation of a $1: 2\left(\mathrm{Eu}^{\mathrm{III}} / \mathrm{L}\right)$ compound in which only one calix[6]arene molecule is bound to the 8-coordinate metal ion through a single phenoxide unit, as shown by its X-ray structure. ${ }^{[23]}$ Replacing nitrate with trifluoromethanesulfonate (triflate) results in the formation of bimetallic 2:1 species $(\mathrm{Ln}=\mathrm{La}, \mathrm{Sm}, \mathrm{Yb})$ in which the two metal cations are anchored on both sides of the macrocycle in the 1,2,3-alternate conformation, which acts as a bidentate ligand, while the coordination sphere of the 7-coordinate $\mathrm{Ln}^{\mathrm{III}}$ ions $(\mathrm{Ln}=\mathrm{Sm}, \mathrm{Yb})$ is completed by one monodentate triflate and one nitrogen donor atom from the pyridine and/or terpyridine. ${ }^{[24]}$
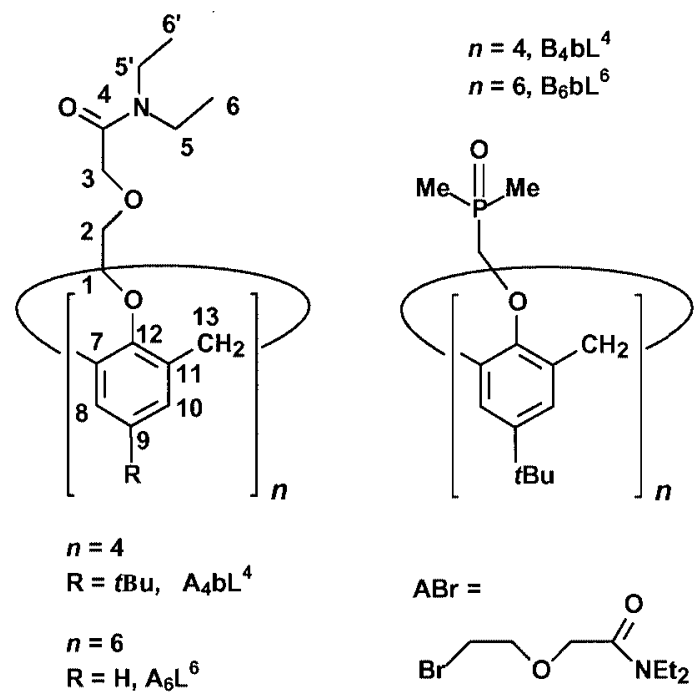

Scheme 1

In this paper, we discuss how the removal of the p-tertbutyl groups influences the conformation of the calix[6]arene derivatized with pendant arms A and, consequently, the stoichiometry of the $\mathrm{Ln}^{\mathrm{III}}$ complexes. Removal of the tert-butyl groups should result in easier conformational interconversion, and a relief in steric hindrance is expected to favor the formation of the 2:1 complexes, contrary to what has been observed for $\mathrm{B}_{6} \mathrm{bL}^{6}$, which forms 1:2 complexes. The calixarene $\mathrm{A}_{6} \mathrm{~L}^{6}$, with tert-butyl groups removed, was therefore synthesized, and characterized both in the solid state and in solution, as well as its 2:1 complex with $\mathrm{Eu}^{\mathrm{III}}$. Molecular mechanics and quantum mechanical calculations were performed to help understand the structures of both the free ligand and the complex.

\section{Results and Discussion}

\section{Synthesis and Characterization of the Substituted Calixarene $\mathbf{A}_{6} \mathbf{L}^{6}$}

The branched calix[6]arene $\mathrm{A}_{6} \mathrm{~L}^{6}$ (Scheme 1) was obtained in two steps via a Williamson reaction (Scheme 2) from the brominated pendant arm $\mathbf{A B r}$, synthesised as described previously, ${ }^{[14]}$ and the calix[6]arene $\mathrm{H}_{6} \mathrm{~L}^{6}$. The hexasodium derivative of calix[6]arene was prepared in toluene, demonstrating that this salt can be formed in a non-polar solvent despite the high fluxionality of calix[6]arene, provided adequate experimental conditions are used i.e. heating, vigorous stirring, and a nitrogen atmosphere to avoid oxidation and protonation of the phenoxide groups. The macrocycle is soluble in $\mathrm{CH}_{2} \mathrm{Cl}_{2}, \mathrm{CHCl}_{3}, \mathrm{CH}_{3} \mathrm{CN}$, toluene, methanol, and ethanol. Its IR spectrum displays an intense band at $1639 \mathrm{~cm}^{-1}$ typical of the carbonyl groups in an $N, N^{\prime}$-disubstituted amide $\left(1646 \mathrm{~cm}^{-1}\right.$ in $\left.\mathbf{A B r}\right)$. The absorption band associated with contributions from the aliphatic ether groups appears at $1126 \mathrm{~cm}^{-1}\left(1119 \mathrm{~cm}^{-1}\right.$ in $\left.\mathbf{A B r}\right)$, medium bands at 1218 and $1045 \mathrm{~cm}^{-1}$ are typical of the phenoxide groups, while the three neighboring aromatic $\mathrm{C}-\mathrm{H}$ groups generate a characteristic symmetric out-ofplane bending at $765 \mathrm{~cm}^{-1}$. In the UV/Vis spectrum, the structured band at $270 \mathrm{~nm}\left(37040 \mathrm{~cm}^{-1}\right)$ with a shoulder at $278 \mathrm{~nm}\left(35970 \mathrm{~cm}^{-1}\right)$ indicates complete functionalization of the phenoxide groups. This structured absorption band is associated with $\pi \rightarrow \pi^{*}$ transitions involving orbitals mainly located on the phenyl rings. A band corresponding to transitions primarily located on the carbonyl groups can be seen at $223 \mathrm{~nm}\left(44840 \mathrm{~cm}^{-1}\right)$ in the diffuse reflectance spectrum.

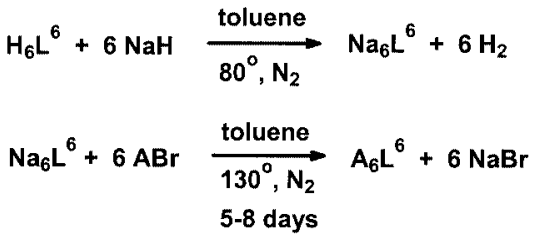

Scheme 2

The ${ }^{1} \mathrm{H}$ NMR spectrum of $\mathrm{A}_{6} \mathrm{~L}^{6}$ in $\mathrm{CD}_{3} \mathrm{CN}$ at room temperature is shown in Figure 1 together with its complete assignment (see Scheme 1 for atomic numbering). The limited number of signals points to a high average symmetry on the NMR time scale. This may be interpreted as a consequence either of fast interconversion processes between the different conformers on the NMR timescale, or of the presence of a single species of high symmetry, such as the 1,3,5 alternate conformation belonging to the $S_{6}$ point group. While the introduction of long complexing arms on the $p$ tert-butylcalix[6]arene moiety may be expected to freeze the oxygen-through-the-annulus rotation, ${ }^{[25,26]}$ removal of the 
bulky tert-butyl groups favors the aromatic-through-the-annulus rotation. Since the latter mechanism has been observed with $O$-substituted $p$-tert-butylcalix[6]arenes, ${ }^{[26]}$ it is reasonable to assume that the lack of substitution on the phenol groups allows for rapid aromatic-through-the-annulus rotation and, hence, the apparent high symmetry observed is the result of fast interconversion between the different conformers.

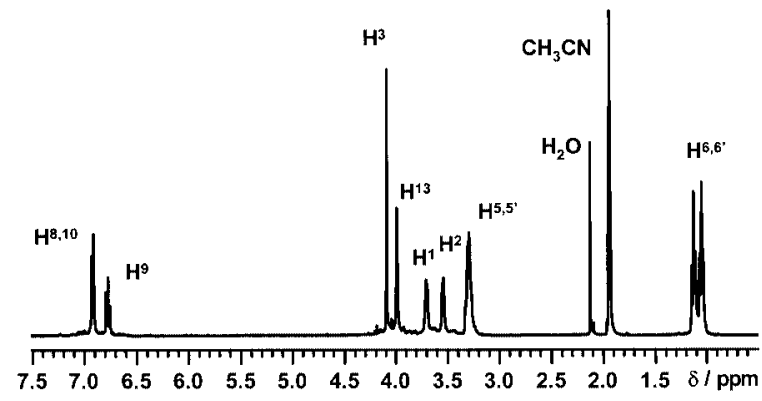

Figure 1. ${ }^{1} \mathrm{H}$ NMR spectrum of $\mathrm{A}_{6} \mathrm{~L}^{6} 10^{-3} \mathrm{M}$ in $\mathrm{CD}_{3} \mathrm{CN}$ at $295 \mathrm{~K}$

A detailed comparison of the chemical shifts of the proton atoms of the complexing arms in $\mathrm{A}_{6} \mathrm{~L}^{6}$ and $\mathrm{A}_{4} \mathrm{bL}^{4}$ further enlightens an unusual point. While the ethyl groups of the amide functions are found essentially at the same chemical shifts in both ligands, signals corresponding to the $\mathrm{H}^{1}$ and $\mathrm{H}^{2}$ protons are shifted significantly upfield (more than $0.4 \mathrm{ppm}$ ) in $\mathrm{A}_{6} \mathrm{~L}^{6}$ compared with $\mathrm{A}_{4} \mathrm{bL}^{4} \cdot{ }^{[14]}{ }^{1} \mathrm{H}$ NMR spectroscopic data of $\mathrm{A}_{4} \mathrm{bL}^{4}$ indeed showed the compound adopting a cone conformation in solution, in which the four complexing arms are held together in closed proximity, thereby providing a suitable octadentate coordination site for lanthanide cations. ${ }^{[14]}$ The X-ray crystal structure of the lutetium complex further showed that a water molecule was encapsulated in the cavity formed by the four dioxo-ethylene bridges $(\mathrm{O}-\mathrm{C} 1-\mathrm{C} 2-\mathrm{O})$, with $\mathrm{H}$-bonding interactions between this water molecule and the oxygen atoms. Interestingly, an elemental analysis of free $\mathrm{A}_{4} \mathrm{bL}^{4}$ revealed the presence of one water molecule, even after the drying process. It was suspected, that the $\mathrm{H}$-bonding interactions with the water molecule are also present in the free ligand in solution, leading to a decrease of the electronic density on the ethylene bridges, and a concomitant upfield shift of the corresponding signals in the ${ }^{1} \mathrm{H}$ NMR spectrum. For the larger and more flexible calix[6]arene, NMR spectroscopic data indicate that the cone conformation is not the most favorable conformation, leading to chemical shifts similar to those found in the brominated $\mathbf{A B r}$ molecule or its hydroxy precursor. The same reasoning can be applied to the corresponding carbon atoms ( $\mathrm{C} 1$ and $\mathrm{C} 2)$, one of which is shifted upfield by $1.1 \mathrm{ppm}$ in $\mathrm{A}_{4} \mathrm{bL}^{4}$ compared with $\mathrm{A}_{6} \mathrm{~L}^{6}$.

${ }^{13} \mathrm{C}\left\{{ }^{1} \mathrm{H}\right\}$ NMR spectra in both $\mathrm{CDCl}_{3}$ and $\mathrm{CD}_{3} \mathrm{CN}$ confirm the fast exchange hypothesis (see Figure $\mathrm{S} 1$ in the Supporting Information; see also the footnote on the first page of this article) since $\delta\left(\mathrm{C}^{13}\right)=30.95 \mathrm{ppm}$ points to a syn orientation of adjacent phenol rings, ${ }^{[27]}$ thus excluding the hypothetical 1,3,5-alternate conformation in which adjacent rings are in an anti conformation. Only four signals are observed for the aromatic carbon atoms, indicating the equivalence of the six aromatic rings on the NMR time scale, and an average hexagonal $\left(D_{6 h}\right)$ symmetry for the calixarene core. All the carbon atoms of the pendant arms also give rise to one signal, except those of the ethyl groups which are split into two components pointing to a somewhat restricted rotation around the amide function.

To substantiate the interpretation of the NMR spectra, we turned to molecular mechanics calculations, and evaluated the $\mathrm{A}_{6} \mathrm{~L}^{6}$ structure using a MOPAC PM3 procedure, taking into account solvent effects (water). The conformer with the lowest energy is shown in Figure 2. It displays a pinched "chair" conformation of the 1,2,3-alternate type. Three consecutive phenol groups are positioned in such a way, that the pendant arms form two cavities predisposed towards metal ion coordination, each built up of three pendant arms, and extending on opposite sides of the macrocycle.

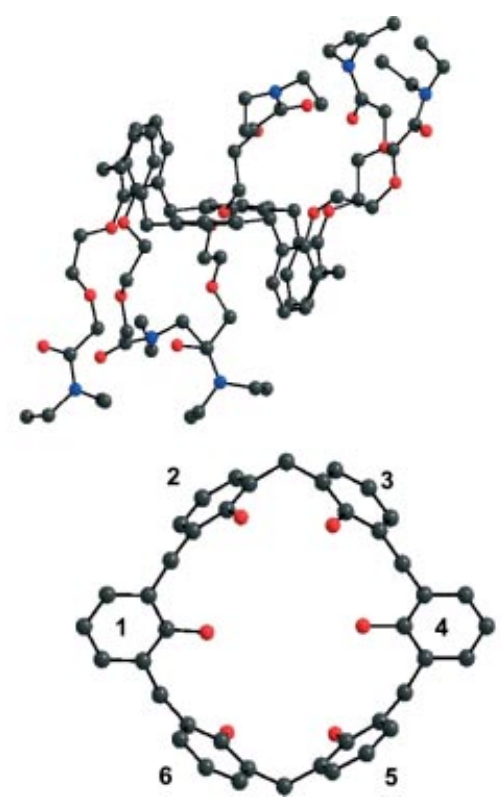

Figure 2. (Top) optimized geometry of $\mathrm{A}_{6} \mathrm{~L}^{6}$ as determined by MOPAC PM3 calculations taking into account the solvent effect (water); (bottom) View of the calixarene core only

\section{Interaction of $\mathrm{A}_{6} \mathrm{~L}^{6}$ with $\mathrm{La}^{\mathrm{III}}$ and $\mathrm{Eu}^{\mathrm{III}}$ in Acetonitrile}

To gain information on the interaction between lanthanide ions and the calixarene $\mathrm{A}_{6} \mathrm{~L}^{6}$, solutions of the latter (typically $10^{-3} \mathrm{M}$ ) were titrated with solutions of lanthanide triflates $\mathrm{Ln}(\mathrm{OTf})_{3} \cdot 6 \mathrm{H}_{2} \mathrm{O}$ (typically $10^{-3} \mathrm{M}, \mathrm{Ln}=\mathrm{La}, \mathrm{Eu}$ ) for ratios $R=\left[\mathrm{Ln}^{\mathrm{III}}\right]_{t} /\left[\mathrm{A}_{6} \mathrm{~L}^{6}\right]_{t}$ varying from 0 to 3 . The spectra are shown in Figure 3 (S2, and S3, see Supporting Information). In all cases, the spectra display broad overlapping signals, probably as a result of fast exchange reactions of the complexed species. This prevented a quantitative treatment. For $R<1$, the free ligand and a complex species coexist in solution. For $R=1$, a distinct $\mathrm{AB}$ spin system can be observed $(\mathrm{Ln}=\mathrm{La})$ with two doublets at 4.45 and 
$3.60 \mathrm{ppm}$ for the methylene proton atoms bridging two phenolic units. This strongly suggests an average cone-like conformation for the 1:1 $\mathrm{LnA}_{6} \mathrm{~L}^{6}$ complex. The broadness of the peaks corresponding to the protons of the arms may be attributed to exchange processes, possibly between forms in which these arms are complexed or not complexed to the metal cation. For $R>1$, the peaks of the non-coordinated ligand disappear, and signals corresponding to at least two species with different $\mathrm{LnA}_{6} \mathrm{~L}^{6}$ stoichiometries can be identified. Since the spectra do not change further when $R$ is increased from 2 to 3 , we conclude that two species form successively in solution, with 1:1 and 2:1 metal-to-ligand ratios. This is in line with the calculated structure of $\mathrm{A}_{6} \mathrm{~L}^{6}$ which shows two sets of three pendant arms extending on opposite sides of the calixarene (cf. Figure 2). Attempts to establish a more quantitative speciation by ES-MS failed due to hydrolysis at high dilution in the capillary during the analysis $\left(T=200^{\circ} \mathrm{C}\right)$. As a result, only monometallic species were detected for $R$ values in the range $1-3$, in addition to free $\mathrm{A}_{6} \mathrm{~L}^{6}$ (Table 1).

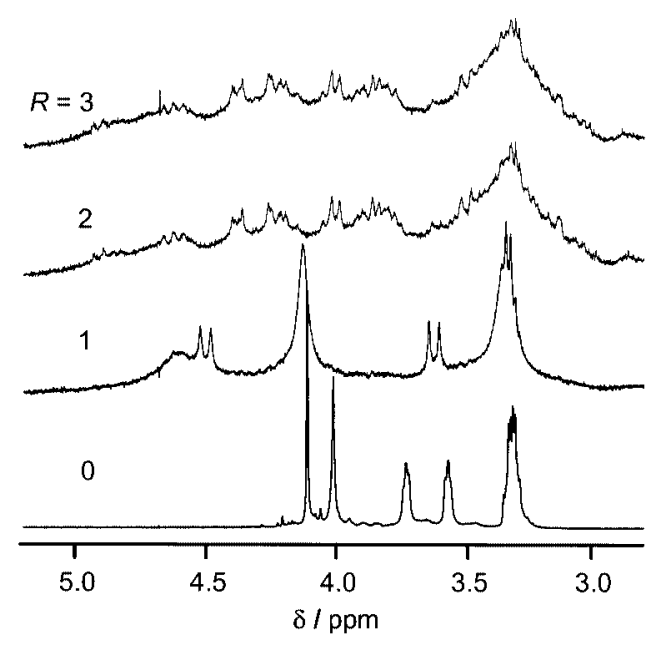

Figure 3. Part of the ${ }^{1} \mathrm{H}$ NMR spectra obtained during the titration of $\mathrm{A}_{6} \mathrm{~L}^{6}$ by $\mathrm{La}(\mathrm{OTf})_{3} \cdot 6 \mathrm{H}_{2} \mathrm{O}$ in $\mathrm{CD}_{3} \mathrm{CN}$ at room temperature; $R=$ $[\mathrm{La}]_{t} /\left[\mathrm{A}_{6} \mathrm{~L}^{6}\right]_{t}$

\section{Isolation and Characterization of the 2:1 $\mathrm{Eu}^{\mathrm{III}} \mathrm{Complex}$}

The complex can be isolated in good yield from stoichiometric mixtures of $\mathrm{A}_{6} \mathrm{~L}^{6}$ and europium triflate in acetonitrile. The elemental analysis is consistent with the formula $\mathrm{Eu}_{2}(\mathrm{OTf})_{6}\left(\mathrm{~A}_{6} \mathrm{~L}^{6}\right) \cdot 9 \mathrm{H}_{2} \mathrm{O}$. Coordination of the carbonyl groups of the pendant arms can be ascertained from the IR data (obtained after drying the pellet at $118{ }^{\circ} \mathrm{C}$ ), the $v_{\mathrm{C}=\mathrm{O}}$ vibration being red-shifted by $25 \mathrm{~cm}^{-1}$ compared with the ligand, pointing to a strong metal-to-ligand interaction. Moreover, the intensity of the band arising from the aliphatic ether functions of the arm is strongly reduced, in line with the coordination of these moieties to the metal ion. The vibration involving contribution from the aromatic ether could not be identified, probably being masked by another band, contrary to what we reported for the $\left[\operatorname{Ln}\left(\mathrm{A}_{4} \mathrm{bL}^{4}\right)\right]^{3+}$ complexes, for which (i) this band is little affected by the complexation, and (ii) the crystal structure of $\left[\mathrm{Lu}\left(\mathrm{A}_{4} \mathrm{bL}^{4}\right)\left(\mathrm{H}_{2} \mathrm{O}\right)\right](\mathrm{OTf})_{3} \cdot 2 \mathrm{Et}_{2} \mathrm{O}$ does not show evidence of any coordination of aromatic ethers. ${ }^{[14]}$ In our case, this suggests some change in the ligand conformation upon complexation and, possibly, coordination of these groups to the metal ion. Other ligand vibrations, for instance the bending $\mathrm{CH}_{2}$ mode $\left(1450 \mathrm{~cm}^{-1}\right)$, and the out-of-plane ring bending mode $\left(760 \mathrm{~cm}^{-1}\right)$, experience small, but characteristic changes upon complexation. In addition, two strong bands at 1030 and $638 \mathrm{~cm}^{-1}$ can be assigned to the $v_{\mathrm{s}}\left(\mathrm{SO}_{2}\right)$ and $v_{\text {as }}\left(\mathrm{SO}_{3}\right)$ modes of coordinated triflate, ${ }^{[28]}$ while the band at $1321 \mathrm{~cm}^{-1}$ is evidence for ionic triflate. Finally, water coordination can be deduced from a sharp band near

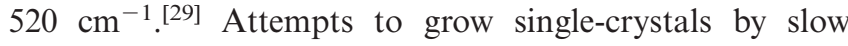
vapor diffusion of diethyl ether or diisopropyl ether in acetonitrile, THF or $\mathrm{MeOH}$, were unsuccessful.

${ }^{1} \mathrm{H}$ NMR spectra obtained during the titration of $\mathrm{A}_{6} \mathrm{~L}^{6}$ with europium triflate (Figure S3, see Supporting Information) revealed that complexation induces freezing of the ligand conformation, resulting in a very complex pattern, which is difficult to interpret. Variable temperature NMR spectra of a $\mathrm{Eu}_{2}(\mathrm{OTf})_{6}\left(\mathrm{~A}_{6} \mathrm{~L}^{6}\right) \cdot 9 \mathrm{H}_{2} \mathrm{O}$ solution in $\mathrm{CD}_{3} \mathrm{CN}$ were recorded up to $75{ }^{\circ} \mathrm{C}$. Although the overall pattern becomes somewhat simplified, the spectrum remains complex. Higher temperatures could not be reached, because the complex experiences de-metallation in DMSO, a solvent in which, for instance, $\mathrm{B}_{6} \mathrm{bL}^{6}$ undergoes complete interconversion of its isomers on the NMR time scale at $132{ }^{\circ} \mathrm{C} .{ }^{[16]}$

\section{Photophysical Properties of $\mathrm{A}_{6} \mathrm{~L}^{6}$ and Its 2:1 $\mathrm{Eu}^{\mathrm{III}}$ Complex}

The photophysical properties of $\mathrm{A}_{6} \mathrm{~L}^{6}$, and of the 2:1 $\mathrm{Eu}^{\mathrm{III}}$ complex have been determined both for solid state samples (295 and $77 \mathrm{~K}$ ), and for frozen acetonitrile solutions $(77 \mathrm{~K})$. The excitation spectrum of the ligand is similar to the absorption and reflectance spectra discussed above. Excitation of a solid sample of $\mathrm{A}_{6} \mathrm{~L}^{6}$ at $275 \mathrm{~nm}$

Table 1. Main species observed in the ES-MS spectra of solutions containing $\mathrm{A}_{6} \mathrm{~L}^{6}$ and $\mathrm{Eu}(\mathrm{Otf})_{6} \cdot 6 \mathrm{H}_{2} \mathrm{O}$ in various proportions (see text)

\begin{tabular}{llll}
\hline Species & Obsd. $m / z$ & Rel. Int. & Calcd. $m / z$ \\
\hline$\left[\mathrm{Eu}(\mathrm{OH})_{3}\left(\mathrm{~A}_{6} \mathrm{~L}^{6}\right)\left(\mathrm{H}_{2} \mathrm{O}\right)_{5}+\mathrm{H}\right]^{+}$ & 1873.4 & $<15 \%$ & 1873.9 \\
{$\left[\mathrm{Eu}(\mathrm{OH})\left(\mathrm{CF}_{3} \mathrm{SO}_{3}\right)\left(\mathrm{A}_{6} \mathrm{~L}^{6}\right)\left(\mathrm{CH}_{3} \mathrm{CN}\right)\right]^{+}$} & 1940.3 & $<15 \%$ & 1939.1 \\
{$\left[\mathrm{Eu}(\mathrm{OH})\left(\mathrm{CF}_{3} \mathrm{SO}_{3}\right)\left(\mathrm{A}_{6} \mathrm{~L}^{6}\right)\left(\mathrm{H}_{2} \mathrm{O}\right)\left(\mathrm{CH}_{3} \mathrm{CN}\right)\right]^{+}$} & 1958.4 & $15-20 \%$ & 1957.1 \\
{$\left[\mathrm{Eu}(\mathrm{OH})\left(\mathrm{CF}_{3} \mathrm{SO}_{3}\right)\left(\mathrm{A}_{6} \mathrm{~L}^{6}\right)\left(\mathrm{H}_{2} \mathrm{O}\right)_{3}\left(\mathrm{CH}_{3} \mathrm{CN}\right)\right]^{+}$} & 1993.8 & $25-50 \%$ & 1993.2 \\
{$\left[\mathrm{~A}_{6} \mathrm{~L}^{6}+\mathrm{H}\right]^{+}$} & 1580.8 & $100 \%$ & 1581.0 \\
\hline
\end{tabular}


$\left(36360 \mathrm{~cm}^{-1}\right)$ and $77 \mathrm{~K}$ yields two emission bands centered at $305 \mathrm{~nm}\left(32790 \mathrm{~cm}^{-1}\right)$, which can be assigned as arising from the ${ }^{1} \pi \pi^{*}$ state, and at $446 \mathrm{~nm}\left(22420 \mathrm{~cm}^{-1}\right)$, attributed to the ${ }^{3} \pi \pi^{*}$ state, as ascertained by the lifetime, which amounts to $104 \pm 8 \mathrm{~ms}$ in frozen acetonitrile solution $(2 \times$ $\left.10^{-3} \mathrm{M}\right)$. This can be compared with $83 \pm 4 \mathrm{~ms}$ for $\mathrm{B}_{6} \mathrm{bL}^{6}$ under the same experimental conditions. ${ }^{[16]}$

The absorption spectrum of the 2:1 complex in acetonitrile $\left(4.74 \times 10^{-5} \mathrm{M}\right)$ displays three bands at $268 \mathrm{~nm}$ $\left(37310 \mathrm{~cm}^{-1}, \varepsilon=9490 \mathrm{~mol}^{-1} \cdot \mathrm{cm}^{-1}\right), 276 \mathrm{~nm}\left(36230 \mathrm{~cm}^{-1}\right.$, $\left.\varepsilon=8650 \mathrm{~mol}^{-1} \cdot \mathrm{cm}^{-1}\right)$, and $293 \mathrm{~nm}\left(34130 \mathrm{~cm}^{-1}, \varepsilon=3380\right.$ $\mathrm{mol}^{-1} \cdot \mathrm{cm}^{-1}$ ). The first two bands are blue-shifted $265 \mathrm{~cm}^{-1}$ compared with those in the uncomplexed ligand. The third band is only present in the complex. The excitation spectrum of the complex, obtained at $10 \mathrm{~K}$ with concomitant monitoring of the ${ }^{5} \mathrm{D}_{0} \rightarrow{ }^{7} \mathrm{~F}_{2}$ transition, reveals the usual $\mathrm{f}-\mathrm{f}$ transitions as well as a broad band in the range of $320-450 \mathrm{~nm}$ with a maximum at $372 \mathrm{~nm}\left(26880 \mathrm{~cm}^{-1}\right)$, which could possibly be associated with a ligand-to-metal charge transfer (LMCT) band. Excitation in the ligand levels yields a luminescence spectrum displaying both ligand-centered and metal-centered ${ }^{5} \mathrm{D}_{0} \rightarrow{ }^{7} \mathrm{~F}_{\mathrm{J}}$ emission bands, pointing to incomplete ligand-to-metal energy transfer. The high-resolution laser-excited excitation spectrum in the range of the ${ }^{5} \mathrm{D}_{0} \leftarrow{ }^{7} \mathrm{~F}_{0}$ transition, monitored via the ${ }^{5} \mathrm{D}_{0} \rightarrow{ }^{7} \mathrm{~F}_{2}$ transition, results in a single, broad component at $17267 \mathrm{~cm}^{-1}$ at $10 \mathrm{~K}$ (full width at half height fwhh $=37$ $\mathrm{cm}^{-1}$ ), and $17280 \mathrm{~cm}^{-1}$ at $295 \mathrm{~K}\left(\mathrm{fwhh}=24 \mathrm{~cm}^{-1}\right)$, indicative of a sample with several slightly different chemical environments for the $\mathrm{Eu}^{\mathrm{III}}$ ion, possibly arising from different conformations of the macrocycle and associated pendant arms. ${ }^{[30]}$ Excitation in either the ${ }^{5} \mathrm{D}_{0} \leftarrow{ }^{7} \mathrm{~F}_{0}$ or ${ }^{5} \mathrm{~L}_{6} \leftarrow{ }^{7} \mathrm{~F}_{0}$ transitions yields relatively broad emission spectra dominated by the hypersensitive ${ }^{5} \mathrm{D}_{0} \rightarrow{ }^{7} \mathrm{~F}_{2}$ transition, which are characteristic of a chemical environment with low symmetry (Figure S4, Supp. Inf.). The relative and corrected intensities of the ${ }^{5} \mathrm{D}_{0} \rightarrow{ }^{7} \mathrm{~F}_{\mathrm{J}}$ transitions are $1.0,7.4,0.1$, and $1.9(10 \mathrm{~K})$ and $1.0,7.2,0.2$, and $2.0(295 \mathrm{~K})$ for $J=1,2,3$, and 4 , respectively.

The lifetimes of the excited ${ }^{5} \mathrm{D}_{0}$ level were measured at 10,77 , and $295 \mathrm{~K}$ both upon ligand and direct metal excitation (Table 2). The luminescence decays of the solid state sample are bi-exponential and temperature dependent, decreasing roughly by a factor of two between $10 \mathrm{~K}$ and room temperature. This is indicative of vibrational and/or electronic radiationless de-activation mechanisms. Here, both processes are probably operating in view of the fluxional nature of the calixarene, and of the LMCT band apparent in the excitation spectrum. Lifetimes measured upon ligand excitation are longer than those obtained through direct excitation of the ${ }^{5} \mathrm{D}_{0}$ level, pointing to a feeding level with a long lifetime, namely the triplet state. High energy vibrations such as those generated by $\mathrm{O}-\mathrm{H}$ groups are known to efficiently de-excite $\mathrm{Ln}^{\mathrm{III}}$ excited levels, ${ }^{[11]}$ and phenomenological equations have been proposed to relate $\Delta k_{\text {obsd. }}=1 / \tau_{\text {obsd. }}-1 / \tau_{\text {ref }}$ where $\tau_{\text {ref }}$ is the lifetime measured on the corresponding deuterated sample or in deuterated water, and the number of water molecules $q$ directly bound to the $\mathrm{Ln}^{\mathrm{III}}$ ion, either in the solid state ${ }^{[32]}$ or in solution. ${ }^{[33]}$ Interpreting our lifetime data along these lines, we note that one lifetime, $\tau_{1}$, is long. It decreases, under direct excitation, from $1.66 \mathrm{~ms}(10 \mathrm{~K})$ to $0.86 \mathrm{~ms}$ ( $295 \mathrm{~K})$. Such a lifetime, at least at low temperature, is consistent with the inner coordination sphere containing no water molecules. The other lifetime, $\tau_{2}$, is much shorter, decreasing from $0.46 \mathrm{~ms}(10 \mathrm{~K})$ to $0.28 \mathrm{~ms}(295 \mathrm{~K})$, under direct excitation of the $\mathrm{Eu}^{\mathrm{III}}$ ion. Taking $\tau_{1}=\tau_{\text {ref }}$ as a first approximation, and $q=1.05 \Delta k_{\text {obsd. }}{ }^{[32]}$ we calculate, that the number of bound water molecules lies between 1.6 $(10 \mathrm{~K})$ and 2.5 (77 and $295 \mathrm{~K})$. The apparent increase in $q$ with increasing temperature could be simply due to outer sphere water molecules hydrogen-bonded to the complex, which become more labile when the temperature increases, or to other vibrational temperature-dependent deactivation processes affecting the de-excitation of the two metal ions differently.

Table 2. Lifetimes (ms) of the ${ }^{5} \mathrm{D}_{0}(\mathrm{Eu})$ level in a solid state sample of $\mathrm{Eu}_{2}(\mathrm{OTf})_{6}\left(\mathrm{~A}_{6} \mathrm{~L}^{6}\right) \cdot 9 \mathrm{H}_{2} \mathrm{O}$ under various experimental conditions

\begin{tabular}{clll}
\hline$T(\mathrm{~K})$ & $\tilde{\mathrm{v}}_{\mathrm{ex}}\left(\mathrm{cm}^{-1}\right)$ & $\tau_{1}(\mathrm{~ms})$ & $\tau_{2}(\mathrm{~ms})$ \\
\hline 10 & 32468 & $2.01 \pm 0.05$ & $0.97 \pm 0.04$ \\
77 & 32468 & $1.71 \pm 0.03$ & $0.48 \pm 0.01$ \\
295 & 32468 & $1.09 \pm 0.02$ & $0.36 \pm 0.01$ \\
10 & 17268 & $1.66 \pm 0.01$ & $0.46 \pm 0.02$ \\
77 & 17268 & $1.19 \pm 0.04$ & $0.31 \pm 0.01$ \\
295 & 17280 & $0.86 \pm 0.02$ & $0.28 \pm 0.01$ \\
$295^{[\mathrm{a}]}$ & 25445 & - & $1.38 \pm 0.02$ \\
\hline
\end{tabular}

[a] Acetonitrile solution $2 \times 10^{-3} \mathrm{M}$; single exponential.

In solution, the ${ }^{5} \mathrm{D}_{0}$ luminescence decay becomes a single exponential, with a value $(1.38 \mathrm{~ms})$ compatible with the absence of $\mathrm{OH}$ oscillators directly bound to $\mathrm{Eu}^{\mathrm{III}}$. Dissolution of the complex results, therefore, in a change in the coordination environment of the $\mathrm{Eu}^{\mathrm{III}}$ ions, since the lifetime is now larger than those observed for the two different sites in the solid state. The quantum yield measured in acetonitrile upon ligand excitation $Q_{\mathrm{Eu}}^{\mathrm{L}}$ amounts to $2.5 \%$, a value similar to that found for $\left[\mathrm{Eu}\left(\mathrm{B}_{6} \mathrm{bL}^{6}\right)_{2}\right]^{3+}$.

\section{Optimized Structure of the Eu ${ }^{\text {III }}$ 2:1 Complex}

In order to confirm the feasibility of our interpretation, we resorted to molecular mechanics calculations to evaluate a potential structure for the 2:1 complex. Several systems were tested, taking into account the experimental data, which suggested that the isolated compound has coordinated triflate anions and water molecules (IR), and two different metal ion sites with $q \approx 0$ and 2 (luminescence lifetimes). It turned out, that the conformer with the lowest energy, as calculated by the MM3 and Conflex procedures, and shown in Figure 4 (see also Table S1 in the Supporting Information), has indeed an asymmetric structure with two 9-coordinate $\mathrm{Eu}^{\mathrm{III}}$ ions. One ion (site I) is bound to two phenolic oxygen atoms, three bidentate arms, and one monodentate triflate anion. The coordination environment of 
the second ion (site II) is somewhat different, with two water molecules replacing the bonding to the phenolic ether atoms. Therefore, the suggested formulation of the 2:1 complex is $\left[\mathrm{Eu}_{2}(\mathrm{OTf})_{2}\left(\mathrm{~A}_{6} \mathrm{~L}^{6}\right)\left(\mathrm{H}_{2} \mathrm{O}\right)_{2}\right]^{4+}$. Generally speaking, the $\mathrm{Ln}-\mathrm{O}$ distances are too long compared with the expected ones for 9-coordinate $\mathrm{Eu}^{\mathrm{III}}$, which lie in the range 2.45-2.60 $\AA^{[34]}$ [averages: 2.72(17) $\AA$ for site I and 2.83(18) $\AA$ for site II]. Relative distances, however, can be discussed. The coordination in site I is comprised of six short bonds (three carbonyl groups, one ether function, and the two phenoxide moieties), and three longer bonds (in 13\%) involving two ether functions and the triflate anion. The situation for site II is somewhat different in that it features only three short bonds (carbonyl groups) identical to those of Site I, all the other distances being 13\% longer. It is noteworthy, that site I builds a more protective cavity around the metal ion than site II does. Moreover, contrary to what was inferred from the ligand design, the phenoxide groups participate more than expected in the bonding (Site I), with $\mathrm{Ln}-\mathrm{O}$ distances similar to those with carbonyl functions.

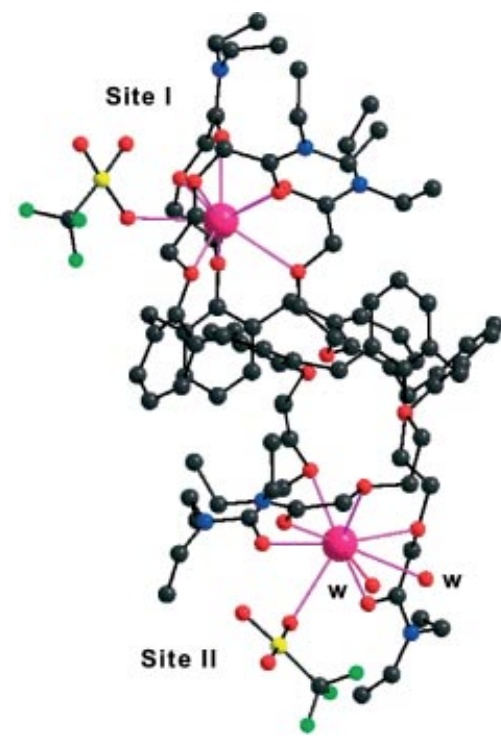

Figure 4. Optimized geometry of the $\mathrm{Eu}^{\mathrm{III}} 2: 1$ complex with $\mathrm{A}_{6} \mathrm{~L}^{6}$ as determined by MM3 Augmented and Conflex CAChe procedures

\section{Conclusion}

The calix[6]arene $\mathrm{A}_{6} \mathrm{~L}^{6}$ exhibits a 1,2,3-alternate conformation in which two sets of three arms extend on opposite sides of the phenoxide framework, henceforth leading to a ditopic ligand able to bind to two metal ions. Complexes with a $2: 1\left(\mathrm{Ln} / \mathrm{A}_{6} \mathrm{~L}^{6}\right)$ stoichiometry could effectively be observed in solution by ${ }^{1} \mathrm{H}$ and ${ }^{13} \mathrm{C}$ NMR spectroscopy, and the $\mathrm{Eu}^{\mathrm{III}}$ complex was isolated. The calculated structure of this complex confirms the results of the luminescence study, and resembles those found experimentally for the 2:1 complexes with $p$-tert-butylcalix[6]arene $\mathrm{H}_{6} \mathrm{bL}^{6}(\mathrm{Ln}=\mathrm{Sm}$,
$\mathrm{Yb}){ }^{[24]}$ The absence of substituents on the narrower rim of $\mathrm{H}_{6} \mathrm{~L}^{6}$ allows easy interconversion between different conformers, through either one of the "tert-butyl through the annulus" or "narrower rim through the annulus" pathways, ${ }^{[35]}$ facilitating the formation of the $2: 1$ complexes. On the other hand, p-tert-butyl-substituted $\mathrm{B}_{6} \mathrm{bL}^{6}$ displays a less labile alternate in-out conformation in which the six phosphanylyl pendant arms are located on the same side of the molecule, and no 2:1 complexes are obtained with this receptor but, instead, compounds with 1:1 and 1:2 stoichiometries can be isolated. ${ }^{[16]}$ This demonstrates once again the versatility of the calixarene frameworks, since a conformation favoring a given stoichiometry of the $\mathrm{Ln}^{\mathrm{III}}$ complexes can be induced by modifying either the wider or the narrower rim of the ligand, a property which should prove useful in the development of convenient extraction systems.

\section{Experimental Section}

Solvents and Starting Materials: Tetrahydrofuran and toluene were distilled from $\mathrm{Na}$, and acetonitrile was distilled from $\mathrm{CaH}_{2} \cdot{ }^{[36]} \mathrm{Di}$ glycolic anhydride, $\mathrm{BH}_{3} \cdot \mathrm{Me}_{2} \mathrm{~S}$ ( 2 M solution in THF), $\mathrm{Et}_{2} \mathrm{NH}, \mathrm{Et}_{3} \mathrm{~N}$, formalin ( $36 \%$ solution), butylphenol, $\mathrm{KOH}, \mathrm{AlCl}_{3}$ phenol, chloroform, acetone, and $\mathrm{SOBr}_{2}$ were purchased from Fluka AG (Buchs, Switzerland) or Merck, and used without further purification.

\section{Syntheses}

Preparation of the Pendant Arm: The brominated ether-amide arm ABr was synthesized as described previously (see Scheme 1). ${ }^{[14]}$ It was dried for $3 \mathrm{~h}$ over $4-\AA$ molecular sieves, which had been previously dried at $240{ }^{\circ} \mathrm{C}$ under high vacuum $\left(24 \mathrm{~h}, 10^{-5}\right.$ Torr $)$.

Calix[6]arene $\mathbf{H}_{6} \mathbf{L}^{\mathbf{6}}$ : p-tert-Butylcalix[6]arene $\left(\mathrm{H}_{6} \mathrm{bL} \mathrm{L}^{6}\right)$ was synthesized according to the procedure reported by Gutsche et al., ${ }^{[37]}$ and its purity checked by TLC analysis: $R_{\mathrm{f}}=0.65$ in $\mathrm{CH}_{2} \mathrm{Cl}_{2} /$ petroleum ether $(1: 1, \mathrm{v} / \mathrm{v}), R_{\mathrm{f}}=0.36$ in acetone/petroleum ether $(1: 9, \mathrm{v} / \mathrm{v})$. The compound was further characterized by $\mathrm{IR},{ }^{1} \mathrm{H}$, and ${ }^{13} \mathrm{C} \mathrm{NMR}$ spectroscopy, and EI mass spectrometry. The tert-butyl groups were then removed following an $\mathrm{AlCl}_{3}$ catalyzed retro-Friedel-Crafts reaction in the presence of phenol. ${ }^{[38]}$ TLC analysis yielded $R_{\mathrm{f}}=$ 0.61 in $\mathrm{CH}_{2} \mathrm{Cl}_{2} /$ petroleum ether $(1: 1, \mathrm{v} / \mathrm{v})$, and $R_{\mathrm{f}}=0.31$ in acetone/ petroleum ether $(1: 9, \mathrm{v} / \mathrm{v})$. It was further characterized by $\mathrm{IR},{ }^{1} \mathrm{H}$, and ${ }^{13} \mathrm{C}$ NMR and EI mass spectrometry.

Functionalization of Calix[6]arene: All operations were performed under strictly anhydrous conditions under nitrogen. Dried calix[6]arene $(135 \mathrm{mg}, 0.21 \mathrm{mmol})$ and $\mathrm{NaH}(60 \%$ in mineral oil, $149 \mathrm{mg}$, $3.73 \mathrm{mmol}$ ) were placed into a $100-\mathrm{mL}$ round-bottomed flask fitted with a nitrogen inlet and a condenser, and dried toluene $(60 \mathrm{~mL})$ was added. The turbid mixture was heated with stirring, becoming almost transparent at $70{ }^{\circ} \mathrm{C}$. The temperature increased spontaneously to $76{ }^{\circ} \mathrm{C}$, hydrogen evolved, and a white emulsion formed. The temperature was slowly increased to $90{ }^{\circ} \mathrm{C}$, and the mixture maintained at this temperature until no fluorescent UV spot corresponding to $\mathrm{H}_{6} \mathrm{~L}^{6}$ was observed on the TLC plate (approximately $1 \mathrm{~h}$ ). The hot emulsion was quickly poured into a $100-$ $\mathrm{mL}$ three-necked round-bottomed flask containing a solution of dried brominated arm $\mathbf{A B r}(808 \mathrm{mg}, 3.4 \mathrm{mmol})$ in dry toluene $(5 \mathrm{~mL})$, which had been previously heated with stirring at $115^{\circ} \mathrm{C}$ for $2 \mathrm{~h}$. More toluene was added $(10 \mathrm{~mL})$, and the temperature was increased to $130^{\circ} \mathrm{C}$. As the reaction progressed the solution became 
turbid and its color changed from brownish-orange to reddish-orange. The reaction was stopped after 6 days. The solid was separated at room temp. by vacuum filtration, and washed with warm toluene until the filtrate became colorless. The filtered organic solution was washed several times with doubly distilled water until the $\mathrm{pH}$ of the latter remained unchanged, and no $\mathrm{AgBr}$ formed upon addition of $2 \% \mathrm{AgNO}_{3}$ to the aqueous phase. During the washing, a white emulsified intermediate phase formed, which disappeared quickly. The organic phase was dried with anhydrous magnesium sulfate, filtered, concentrated at $40{ }^{\circ} \mathrm{C}$, and finally evaporated under vacuum $\left(10^{-2}\right.$ Torr $)$ at $60-70{ }^{\circ} \mathrm{C}$. A deep orange glassy-solid was obtained (ca. $150 \mathrm{mg}$ ) which was ground up. $n$-Hexane $(20 \mathrm{~mL})$ was added, the mixture was stirred and heated to $45^{\circ} \mathrm{C}$ for $30 \mathrm{~min}$, and the yellow solution was separated. This step was repeated until the solution became colorless. The bulk of the solvent was separated, the remaining solvent removed under vacuum $\left(10^{-2}\right.$ Torr $)$, and the orange waxy solid dried at $70{ }^{\circ} \mathrm{C}$ under high vacuum $\left(10^{-5}\right.$ Torr $)$ for 1 day. It was then re-dissolved in a minimum amount of methanol, and diisopropyl ether was added until cloudiness was observed. This mixture was left in the refrigerator overnight to induce precipitation. Small and slightly yellow, brilliant glassy crystals formed after 2 days, which were collected and dried at $100^{\circ} \mathrm{C}$ under high vacuum $\left(10^{-5}\right.$ Torr $)$ for $48 \mathrm{~h}$. The final deliquescent compound (66 mg, $0.042 \mathrm{mmol}, 20 \%$ yield) was then characterized, $\mathrm{C}_{90} \mathrm{H}_{126} \mathrm{~N}_{6} \mathrm{O}_{18}$ (Mol wt. 1580.02). IR $\left(\mathrm{KBr}, \mathrm{cm}^{-1}\right): \tilde{v}=1639$ $\left(v_{\mathrm{C}=\mathrm{O}}\right), 1249\left(v_{\mathrm{C}-\mathrm{O}-\mathrm{C}}\right), 1126\left(v_{\mathrm{O}-\mathrm{CH}_{2}}\right), 1218$ and $1045\left(v_{\mathrm{Ar}-\mathrm{O}}\right), 765$ $\left(v_{\mathrm{C}-\mathrm{H}}\right) . \mathrm{UV} / \mathrm{Vis}$ (dried and degassed spectroscopic grade $\mathrm{CH}_{3} \mathrm{CN}$ ): $\lambda=270,278 \mathrm{~nm}$. Diffuse reflectance $(5 \%$ in $\mathrm{MgO}): 44840(\mathrm{C}=\mathrm{O})$ and 36630 (phenyl) $\mathrm{cm}^{-1}$. ES-MS $\left(10^{-4} \mathrm{M}, \mathrm{CH}_{3} \mathrm{CN}\right): \mathrm{m} / \mathrm{z}=1580.82$ $\left([\mathrm{M}+\mathrm{H}]^{+}\right.$, calcd. 1581.03), $1602.86\left([\mathrm{M}+\mathrm{Na}]^{+}\right.$calcd. 1603.02). ${ }^{1} \mathrm{H}$ NMR $\left(10^{-3} \mathrm{M}, \mathrm{CD}_{3} \mathrm{CN}, 400 \mathrm{MHz}\right): \delta=6.94\left(\mathrm{~d},{ }^{2} J=7.44 \mathrm{~Hz}\right.$, $\left.12 \mathrm{H}, \mathrm{H}^{8}, \mathrm{H}^{10}\right), 6.79\left(\mathrm{t},{ }^{3} J=7.44 \mathrm{~Hz}, 6 \mathrm{H}, \mathrm{H}^{9}\right), 4.11\left(\mathrm{~s}, 12 \mathrm{H}, \mathrm{H}^{3}\right)$, $4.00\left(\mathrm{~s}, 12 \mathrm{H}, \mathrm{H}^{13}\right), 3.72$ (broad, $\left.12 \mathrm{H}, \mathrm{H}^{1}\right), 3.56$ (broad, $12 \mathrm{H}, \mathrm{H}^{2}$ ), $3.35-3.25\left(\mathrm{~m}, 24 \mathrm{H}, \mathrm{H}^{5}, \mathrm{H}^{5^{\prime}}\right), 2.14\left(\mathrm{~s}, 4 \mathrm{H}, 2 \mathrm{H}_{2} \mathrm{O}\right), 1.14\left(\mathrm{t},{ }^{3} \mathrm{~J}=\right.$ $\left.7.1 \mathrm{~Hz}, 18 \mathrm{H}, \mathrm{H}^{6}, \mathrm{H}^{6^{\prime}}\right), 1.07\left(\mathrm{t},{ }^{3} J=7.1 \mathrm{~Hz}, 18 \mathrm{H}, \mathrm{H}^{6}, \mathrm{H}^{6^{\prime}}\right) \mathrm{ppm}$. ${ }^{13} \mathrm{C}\left\{{ }^{1} \mathrm{H}\right\}$ NMR $\left(1 \times 10^{-3} \mathrm{M}, \mathrm{CD}_{3} \mathrm{CN}, 50 \mathrm{MHz}\right): \delta=168.9\left(\mathrm{C}^{4}\right)$, $155.8\left(\mathrm{C}^{12}\right), 135.7\left(\mathrm{C}^{7}, \mathrm{C}^{11}\right), 129.8\left(\mathrm{C}^{9}\right), 124.8\left(\mathrm{C}^{8}, \mathrm{C}^{10}\right), 73.1,71.3$ $\left(\mathrm{C}^{1}, \mathrm{C}^{2}\right), 71.0\left(\mathrm{C}^{3}\right), 41.9,40.5\left(\mathrm{C}^{5}, \mathrm{C}^{5^{\prime}}\right), 31.0\left(\mathrm{C}^{13}\right), 14.7,13.3\left(\mathrm{C}^{6}\right.$, $\left.\mathrm{C}^{6^{\prime}}\right) \mathrm{ppm}$.

Synthesis of the Complex: $\mathrm{Eu}\left(\mathrm{CF}_{3} \mathrm{SO}_{3}\right)_{3} \cdot 6 \mathrm{H}_{2} \mathrm{O}(21 \mathrm{mg}, 0.026 \mathrm{mmol})$ was dissolved in dry $\mathrm{MeCN}(2 \mathrm{~mL})$ at $36{ }^{\circ} \mathrm{C}$ with stirring under $\mathrm{N}_{2}$, and $\mathrm{A}_{6} \mathrm{~L}^{6}(20.5 \mathrm{mg}, 0.013 \mathrm{mmol})$ in dry $\mathrm{MeCN}(4 \mathrm{~mL})$ was added dropwise. The resultant mixture was stirred for $1 \mathrm{~h}$, cooled to room temp., and stirred for a further $4 \mathrm{~h}$. The solvent was partially evaporated under vacuum, and diisopropyl ether was added dropwise until cloudiness appeared. The mixture was left overnight at $-20{ }^{\circ} \mathrm{C}$. The precipitate was centrifuged, washed with diisopropyl ether $(2 \mathrm{~mL})$, and dried under vacuum $\left(10^{-2}\right.$ Torr $)$ at room temp., and then at $80^{\circ} \mathrm{C}$ for $24 \mathrm{~h}$ under high vacuum $\left(10^{-5}\right.$ Torr), yielding a pale pink hygroscopic compound (34 mg, yield $82 \%$ ). $\mathrm{Eu}_{2}\left(\mathrm{CF}_{3} \mathrm{SO}_{3}\right)_{6} \cdot \mathrm{A}_{6} \mathrm{~L}^{6} \cdot 9 \mathrm{H}_{2} \mathrm{O}, \quad \mathrm{C}_{96} \mathrm{H}_{144} \mathrm{Eu}_{2} \mathrm{~F}_{18} \mathrm{~N}_{6} \mathrm{O}_{45} \mathrm{~S}_{6} \quad$ (2940.51): calcd. C 39.2, H 4.8, N 2.9; found C 38.8, H 4.9, N 2.8. IR ( $\mathrm{KBr}$,

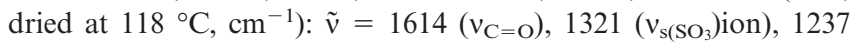
$\left(v_{\mathrm{s}(\mathrm{C}-\mathrm{O}-\mathrm{C})}\right), 1030\left(v_{\mathrm{s}\left(\mathrm{SO}_{2}\right)}\right), 760\left(v_{\mathrm{C}-\mathrm{H}}\right), 638\left(\delta_{\mathrm{as}\left(\mathrm{SO}_{3}\right)}\right), 520\left(v_{\mathrm{H}_{2} \mathrm{O}}\right)$. Diffuse reflectance $(5 \%$ in $\mathrm{MgO}): 37310,36230,34130 \mathrm{~cm}^{-1}$.

Spectroscopic and Analytical Measurements: IR spectra were measured with a Mattson Alpha Centauri FT spectrometer as KBr pellets for solid samples, and films on $\mathrm{AgCl}$ for oily samples. ES-MS spectra were measured with a Finnigan SSQ 710C spectrometer driven by a Digital Personal station 5000/25 using $10^{-4}$ M solutions in methanol or dry acetonitrile, and a $\mathrm{MeOH} / \mathrm{HCO}_{2} \mathrm{H}$ mixture as eluent. NMR spectra were recorded with Bruker AM-360
(360 MHz) or DRX Advance 400 (400 MHz) spectrometers; chemical shifts $\delta$ are given with respect to TMS or $\mathrm{CD}_{3} \mathrm{CN}$. Low resolution luminescence spectra of solid state samples (295 and $77 \mathrm{~K}$ ) were recorded with a Perkin-Elmer LS-50B spectrofluorimeter. Lifetimes of solutions (data reported are averages of at least five determinations), and quantum yields were measured with the same instrument. The quantum yield of the metal-centered luminescence was determined in degassed and anhydrous $\mathrm{CH}_{3} \mathrm{CN}$ at room temperature with respect to $[\mathrm{Eu}(\mathrm{L})]^{3+} 3 \times 10^{-5} \mathrm{M}$ in acetonitrile $\left(Q_{\text {abs }}=23 \%{ }^{[39]}\right)$ where $\mathrm{L}$ is a cyclen derivative $\{1,3,7,10$-tetrakis $[N$ (4-phenylacetyl)carbamoylmethyl]-1,4,7,10-tetraazacyclododecane\} using the following formula:

\section{$Q_{x} / Q_{r}=\left[A_{r}(\lambda) / A_{x}(\lambda)\right] \cdot\left[D_{x} / D_{r}\right] \cdot\left[n_{\mathrm{x}}^{2} / n_{\mathrm{r}}^{2}\right]$}

where the subscript $r$ stands for the reference, and $x$ for the sample. $A$ is the absorbance at the excitation wavelength $\lambda, n$ the refractive index (1.344 for solution in $\mathrm{CH}_{3} \mathrm{CN}$ and 1.333 for the solution in water), and $D$ the integrated luminescence intensity. The same excitation wavelength $(279 \mathrm{~nm})$ and absorbance $(0.27)$ were used for the sample and the reference, and a bandpass filter $(350 \mathrm{~nm}$ or $390 \mathrm{~nm}$ ) was inserted to eliminate both the Rayleigh diffusion band and second order spectra. High resolution laser excited luminescence spectra were recorded using published procedures. ${ }^{[40]}$ Lifetime data for solid samples were measured at different temperatures under pulsed excitation provided by a FL-3001 dye laser from Lambda Physik coupled to an excimer XeCl laser EMG-101-MSC from Lambda Physik. Elemental analyses were performed by Dr H. Eder (Microchemical Laboratory, University of Geneva).

Semi-Empirical Calculations: The optimized structures and energy minima of the free ligand, and of the 2:1 complex were calculated by using MM3 augmented and CONFLEX procedures, respectively, from the CAChe Pro 5.02 or 5.04 program package for Windows $^{\circledR}$ (Fujitsu Ltd., 2000-2002). The structure of $\mathrm{A}_{6} \mathrm{~L}^{6}$ was further optimized with respect to its enthalpy of formation by MOPAC PM3 molecular orbital calculations using the same program package. The effect of solvent (water) was taken into account using the COSMO procedure built into CAChe Pro. Experimental data for both the free ligand and the $\mathrm{Eu}^{\mathrm{III}}$ complex (IR, NMR, luminescence) were taken into account for optimizing the calculations.

\section{Acknowledgments}

This work was supported through grants from the Swiss National Science Foundation, and by Conacyt (México), project Nr. 36689E. We thank Véronique Foiret for her help in gathering the luminescence data.

[1] C. D. Gutsche, Calixarenes Revisited, Monographs in Supramolecular Chemistry (Ed.: J. F. Stoddart), The Royal Society of Chemistry, Cambridge, 1998.

[2] Z. Asfari, V. Böhmer, J. M. Harrowfield, J. Vicens, Calixarenes 2001, Kluwer Academic Publishers, Dordrecht, 2001.

[3] F. Cadogan, K. Nolan, D. Diamond, in Calixarenes 2001 (Eds.: Z. Asfari, V. Böhmer, J. M. Harrowfield), Kluwer Academic Publishers, Dordrecht, 2001, chapter 34, 627-641.

[4] C. Dieleman, S. Steyer, C. Jeunesse, D. Matt, J. Chem. Soc., Dalton Trans. 2001, 2508-2517.

[5] D. M. Roundhill, Prog. Inorg. Chem. 1995, 43, 533-592.

[6] P. Thuery, M. Nierlich, J. M. Harrowfield, M. Ogden, in Calixarenes 2001 (Eds.: Z. Asfari, V. Böhmer, J. M. Harrowfield, J. Vicens), Kluwer Academic Publishers, Dordrecht, 2001, chapter 30, 561-582.

[7] J.-C. G. Bünzli, F. Besançon, F. Ihringer, Calixarenes for Separ- 
ations (Eds.: G. J. Lumetta, R. D. Rogers, A. Gopalan), American Chemical Society, Washington D. C., 2000, ACS Symposium Series, vol. 757, chapter 14, 179-194.

[8] J. Rebek, Chem. Commun. 2000, 637-643.

[9] J. L. Atwood, L. J. Barbour, M. J. Hardie, C. L. Raston, Coord. Chem. Rev. 2001, 222, 3-32.

[10] Calixarenes for Separations, ACS Symposium Series (Eds.: G. J. Lumetta, R. D. Rogers, A. Gopalan), American Chemical Society, Washington D. C., 2000, ACS Symposium Series, vol. 757.

[11] J. F. Dozol, V. Lamare, N. Simon, R. Ungaro, A. Casnati, $\mathrm{Ca}$ lixarenes for Separations (Eds.: G. J. Lumetta, R. D. Rogers, A. Gopalan), American Chemical Society, Washington D. C., 2000, ACS Symposium Series, vol. 757, chapter 2, 12-25.

${ }^{[12]}$ F. Arnaud-Neu, M.-J. Schwing-Weill, F. Dozol, Calixarenes 2001 (Eds.: Z. Asfari, V. Böhmer, J. M. Harrowfield, J. Vicens), Kluwer Academic Publishers, Dordrecht, 2001, chapter 35, $642-662$.

${ }^{[13]}$ P. D. Beer, G. D. Brindley, D. B. Fox, A. Grieve, M. I. Ogden, F. Szemes, M. G. B. Drew, Dalton Trans. 2002, 3101-3111.

${ }^{[14]}$ F. de M. Ramirez, L. J. Charbonnière, G. Muller, R. Scopelliti, J.-C. G. Bünzli, J. Chem. Soc., Dalton Trans. 2001, 3205-3213.

${ }^{[15]}$ L. Le Saulnier, S. Varbanov, R. Scopelliti, M. Elhabiri, J.-C. G. Bünzli, J. Chem. Soc., Dalton Trans. 1999, 3919-3925.

${ }^{[16]}$ F. de M. Ramirez, S. Varbanov, C. Cécile, G. Muller, N. FatinRouge, R. Scopelliti, J.-C. G. Bünzli, Dalton Trans. 2002, 4505-4513.

${ }^{[17]}$ F. de M. Ramirez, S. Varbanov, J.-C. G. Bünzli, unpublished work, 2003.

${ }^{[18]}$ R. Ludwig, K. Inoue, T. Yamato, Solv. Extr. Ion Exch. 1993, $11,311-330$

${ }^{[19]}$ R. Ludwig, D. Lentz, T. K. D. Nguyen, Radiochim. Acta 2000, $88,335-343$

${ }^{[20]}$ T. Oshima, T. Yamamoto, K. Ohto, M. Goto, F. Nakashio, S. Furusaki, Solvent Extr. Res. Develop. (Japan) 2001, 8 , 194-204.

${ }^{[21]}$ E. M. Georgiev, J. Clymire, G. L. McPherson, D. M. Roundhill, Inorg. Chim. Acta 1994, 227, 293-296.

${ }^{[22]}$ N. Sato, I. Yoshida, S. Shinkai, Chem. Lett. 1993, 1261-1264.

${ }^{[23]}$ L. M. Engelhardt, B. M. Furphy, J. M. Harrowfield, D. L. Kep- ert, A. H. White, F. R. Wilner, Aust. J. Chem. 1988, 41, $1465-1476$

${ }^{[24]}$ P. C. Leverd, D. Rinaldo, M. Nierlich, Eur. J. Inorg. Chem. 2001, 2021-2025.

${ }^{[25]}$ A. Casnati, P. Minari, A. Pochini, R. Ungaro, J. Chem. Soc., Chem. Commun. 1991, 1413-1414.

${ }^{[26]}$ K. Araki, N. Hashimoto, H. Otsuka, T. Nagasaki, S. Shinkai, Chem. Lett. 1993, 829-832.

[27] C. Jaime, J. De Mendoza, P. Prados, P. M. Nieto, C. Sanchez, J. Org. Chem. 1991, 56, 3372-3376.

[28] M. E. M. Hamidi, J.-L. Pascal, Polyhedron 1994, 13, $1787-1792$.

${ }^{[29]}$ K. Nakamoto, Infrared and Raman Spectra of Inorganic and Coordination Compounds. Part A. Theory and Applications in Inorganic Chemistry, Wiley Interscience, New York, 1997.

${ }^{[30]}$ F. Nicolo, D. Plancherel, G. Chapuis, J.-C. G. Bünzli, Inorg. Chem. 1988, 27, 3518-3526.

[31] J.-C. G. Bünzli, Spectroscopic Properties of Rare Earths in Optical Materials (Eds.: G. K. Liu, B. Jacquier), Springer Verlag, Berlin, 2004, chapter 11 , in press.

${ }^{[32]}$ W. de W. Horrocks Jr., D. R. Sudnick, J. Am. Chem. Soc. 1979 , 101, 334-340.

${ }^{[33]}$ R. M. Supkowski, W. de W. Horrocks Jr., Inorg. Chim. Acta 2002, 340, 44-48.

${ }^{[34]}$ J.-C. G. Bünzli, in Rare Earths (Eds.: R. Saez Puche, P. Caro), Editorial Complutense, Madrid, 1998, 223-259.

${ }^{[35]}$ W. P. van Hoorn, F. C. J. M. van Veggel, D. N. Reinhoudt, $J$. Phys. Chem. 1998, 102, 6676-6681.

${ }^{[36]}$ D. D. Perrin, W. L. F. Armarego, Purification of Laboratory Chemicals, Pergamon Press, Oxford, 1988.

${ }^{[37]}$ C. D. Gutsche, B. Dhawan, M. Leonis, D. Stewart, Org. Synth 1990, 68, 238-242.

${ }^{[38]}$ C. D. Gutsche, L. G. Lin, Tetrahedron 1986, 42, 1633-1640.

${ }^{[39]}$ G. Zucchi, A.-C. Ferrand, R. Scopelliti, J.-C. G. Bünzli, Inorg. Chem. 2002, 41, 2459-2465.

${ }^{[40]}$ J.-C. G. Bünzli, A. Milicic-Tang, Inorg. Chim. Acta 1996, 252, $221-228$

Received November 7, 2003 Early View Article Published Online April 7, 2004 